\title{
Clinical effectiveness of compounded topical medications in oral medicine: a meta-analysis
}

\author{
Her Basuki Margono', Irna Sufiawati² \\ 'Oral Medicine Residency Program, Faculty of Dentistry, Padjadjaran University, Bandung 40132, West Java, Indonesia. \\ ${ }^{2}$ Department of Oral Medicine, Faculty of Dentistry, Padjadjaran University, Bandung 40132, West Java, Indonesia.
}

Correspondence to: Dr. Irna Sufiawati, Department of Oral Medicine, Faculty of Dentistry, Padjadjaran University: Jl. Sekeloa Selatan I, Bandung 40132, West Java, Indonesia. E-mail: irna.sufiawati@fkg.unpad.ac.id

How to cite this article: Margono HB, Sufiawati I. Clinical effectiveness of compounded topical medications in oral medicine: a meta-analysis. Stomatological Dis Sci2020;4:3. http://dx.doi.org/10.20517/2573-0002.2019.18

Received: 16 Oct 2019 First Decision: 11 Nov 2019 Revised: 14 May 2020 Accepted: 21 Jul 2020 Published: 19 Aug 2020

Academic Editor: Letizia Perillo Copy Editor: Cai-Hong Wang Production Editor: Jing Yu

\begin{abstract}
Aim: To assess the evidence of the efficacy and safety of compounded topical medications in oral medicine cases.

Methods: Electronic databases were searched from inception to October 2019 for studies that evaluated compounded topical medications in oral medicine cases to assess their efficacy and safety. Search terms included drug compounding, topical administration, clinical efficacy, and oral lesions. Only randomized controlled trials (RCTs) or cross-over trials of compounded topical drug versus non-compounded drug or placebo or standard treatment were included. The exclusion criteria included compounded topical medications with herbal ingredients in the intervention group to compare with the non-compounded drug. The primary outcome measure was a clinical resolution of the oral lesions. The secondary outcome measure was pain resolution. Adverse events of interventions were discussed. The quality of RCTs was assessed using the Cochrane risk of bias tool (RoB 2.0). The data were synthesised in a fixed-effect model using RevMan 5. The evidence across studies for an outcome and decision of recommendations was assessed using GRADE criteria for the subgroup of included studies selected in meta-analysis.
\end{abstract}

Results: Of 90 studies, 27 studies were included in the meta-analysis. Overall, only $8 \%$ of included studies were assessed as being at low risk of bias. The compounded topical preparation of antiviral with corticosteroids appeared to be effective for reducing oral ulcers but not pain resolution in herpes labialis. The use clobetasol propionate $0.05 \%$ in mucoadhesive base for oral lichen planus, pilocarpine $\mathrm{HCl} 5 \mathrm{mg}$ lozenge for radiation-induced xerostomia in head and neck cancer patients, amlexanox 5\% in mucoadhesive base and doxycycline hyclate $100 \mathrm{mg}$ in denture adhesive base for recurrent aphthous stomatitis, and morphine $0.2 \%$ mouthwash in controlling oral

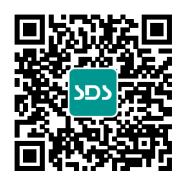


mucositis pain appeared to be beneficial. The use of allopurinol, granulocyte-macrophage colony-stimulating factor, and iseganan $0.3 \%$ mouthwash were not sufficient for reducing oral mucositis severity.

Conclusion: Some compounded topical medications may be effective for the treatment of oral medicine cases. Future well-designed studies using standardised measures are needed to provide high-quality evidence in evaluating the efficacy and safety of compounded topical medications for the management of oral mucosal diseases.

Keywords: Clinical efficacy, drug compounding, meta-analysis, oral medicine, topical administration

\section{INTRODUCTION}

The scope of patient management in oral medicine clinical practice is typically approached by the nonsurgical or pharmacological intervention of orofacial diseases of patients with complex medical conditions. Oral medicine specialists often work with a multidisciplinary team and are involved with chronic, recurrent, painful, or even life-threatening diseases to deliver comprehensive patient care ${ }^{[1]}$.

In oral medicine clinical practice, the drug classes usually used in topical therapies by specialists include corticosteroids, antivirals, antifungals, and nonsteroidal anti-inflammatory drug $\mathrm{s}^{[2]}$. The use of topical drug delivery that is locally absorbed and acts directly at the affected site may provide greater efficacy and fewer side effects than systemically delivered medications. Apart from that, few topical formulations have been designed specifically to treat oral mucosal diseases ${ }^{[3]}$.

For a variety of oral medicine cases, the use of compounded topical medications is a pharmacological treatment option due to limited availability of commercial drug products or provide for patient-specific conditions, such as paediatric population, patients with dysphagia, hard to reach areas in the oral cavity, and when a sugar-free or alcohol-free preparation is needed ${ }^{[4]}$. In many instances, prescriptions for oral medicine conditions are used off-label, and mostly based on expert opinion and experience ${ }^{[1-4]}$.

Despite its benefit of use, there is a lack of evidence-based practice (EBP) guidelines or recommendations regarding the clinical efficacy and patient safety in the utilization of compounded topical medications in the management of oral medicine cases.

Hence, this meta-analysis aimed to investigate the current evidence supporting the clinical efficacy and safety of compounded topical medications for the treatment of a variety of oral lesions in oral medicine cases.

\section{METHODS}

This review followed a detailed protocol in the methodology of Preferred Reporting Items for Systematic Reviews and Meta-Analysis (PRISMA) ${ }^{[5]}$. The study was registered with ID number reviewregistry 898 and can be accessed online (http://www.researchregistry.com/browse-the-registry\#registryofsystematicreviews meta-analyses/).

\section{Eligibility criteria}

The PICO (Population, Intervention, Comparator, and Outcome) ${ }^{[5]}$ model and pre-set criteria on study inclusion and exclusion were determined to answer this study question: What is the clinical efficacy and safety of compounded topical medications for the treatment of a variety of oral lesions in oral medicine cases? The inclusion criteria included randomized controlled trials (RCTs) or cross-over trials, human 
studies with any age, gender, and ethnicity, drug compounding as defined by WHO criteria ${ }^{[6]}$, and no restriction on the specific length of treatment duration or follow-up, and non-English language papers were considered where translation was available. The exclusion criteria included compounded topical medications with herbal ingredients in the intervention group and the testing of non-compounded drug (commercially available drugs).

\section{Information sources and search strategy}

All studies relevant to the review were identified by searching electronic databases including PubMed, Cochrane Oral Health, Cochrane Library, EBSCOhost, ADA Center for Evidence-Based Dentistry (EBD), BMJ EBM, DOAJ, SciELO, clinicaltrials.gov, WHO ICTRP, Google Scholar, and grey literature published from inception to October 2019. Medical Subject Headings terms were used by combining keywords using Boolean operators such as AND/OR. The terms would be followed by truncation symbols such $a^{*}$, if appropriate. The following keywords were used to search in different electronic databases: drug compounding, topical administration, clinical efficacy, and oral lesions.

\section{Study selection and data collection process}

Titles and abstracts (when available) of all studies identified were examined independently by one review author (HBM). When there was insufficient data in an abstract to determine its status, the full manuscript was obtained and assessed independently by two review authors (HBM and IS). Disagreements were resolved by discussion. All articles that did not meet the criteria were excluded. A flowchart of the study selection processes according to PRISMA four-phase flow was generated.

\section{Data extraction and methodological quality assessment}

All the relevant data of each included study, including characteristics of studies (type of case, author, year of publication, and location), characteristics of patients (age and sex ratio), characteristics of interventions (compounded topical medication, formulation, dose, frequency of application, and treatment duration), and adverse events (AEs) were extracted and summarized in a data extraction form.

The included studies underwent quality appraisal, which was independently performed by one review author (HBM) using templates in accordance with the Cochrane risk of bias tool (RoB 2.0) across 5 domains (randomization process, deviations from intended interventions, missing outcome data, measurement of the outcome, and selection of the reported result $)^{[7]}$. The results were rated high risk, some concerns, or low risk and collated into a summary and graph.

\section{Summary measures and synthesis of results}

The primary outcomes compared the efficacy between compounded topical medications and control groups (placebo or standard treatment) based on clinical resolution of oral lesions, either partial or complete response, as measured by any clinical assessment criteria or scale of each specific disease. The secondary outcomes were pain resolution, either partial or complete response, as measured by visual analogue scale or other patient-reported outcome measures (PROMs). One of the outcomes was selected if studies did not measure both outcomes. The safety of interventions as measured by the incidence of AEs was discussed.

The data were abstracted using a $2 \times 2$ contingency table for two independent events or outcomes (participants with clinical resolution of oral lesions or not and pain resolution or not). If the data extraction of binary outcome measures were not possible, the continuous data were abstracted by mean difference, standard deviation, and sample sizes. The included studies were subgrouped and analysed on the basis of the case and intervention category. The meta-analysis of the data was undertaken if no substantial clinical and methodological heterogeneity was identified. All data were then pooled by calculating mean difference or risk ratio (RR) together with the $95 \%$ confidence interval (CI) using a fixed-effect model for two independent outcomes: clinical resolution of oral lesions and pain. Heterogeneity was assessed 
using Cochran's Q statistic with $\mathrm{I}^{2}$ statistic above 50\% indicating substantial heterogeneity. Funnel plot for the detection of publication bias and subgroup analysis to investigate statistical heterogeneity would be applied when the number of trials was at least ten ${ }^{[8]}$. The GRADE (Grades of Recommendation, Assessment, Development and Evaluation Working Group) criteria across 5 domains (limitations in design, inconsistency, indirectness, imprecision, and reporting bias) were used to decide the quality of the evidence for each outcome across studies. The results were expressed in one of four grades: high, moderate, low, and very low ${ }^{[9]}$.

\section{RESULTS}

\section{Study selection}

A total of 90 studies were identified for inclusion in this review. The search of studies provided a total of 2991 articles. There were 2901 records excluded on the basis of duplication, unavailable full text, or not meeting the criteria. Of these, 90 studies met the inclusion criteria and were included in the systematic review. Only twenty-seven studies were included in the meta-analysis. The PRISMA four-phase flow diagram indicating the study selection is presented in Supplementary Figure 1.

\section{Quality assessment: risk of bias}

Of the 90 included studies ${ }^{[10-100]}$, seven studies were judged as low risk of bias ${ }^{[10,39-41,48,49,80]}$, fifty-four were judged as some concerns ${ }^{[11,12,14-18,25,27-30,33,34,42,47,50-56,58-60,62-64,66,67,69-73,75-77,81,82,84-86,88,90-94,96-100]}$, and twenty-nine studies were judged as high risk of bias ${ }^{[13,19-24,26,31,32,35-38,43-46,57,61,65,68,74,78,79,83,87,89,95]}$. Supplementary Figures 2 and 3 summarize the findings of the quality assessment.

\section{Study characteristics}

In general, there were clinical heterogeneity variables in terms of age, baseline disease severity, ethnicity, comorbidities, and other psychosocial variables as well in the included studies. There was no trial specific to the paediatric population. All participants enrolled in the studies underwent a clinical diagnosis with or without laboratory assessment. Methodological heterogeneity was also observed in terms of outcome measurement scale. All included studies were published in English, except one in Bahasa Indonesia.

The 90 included studies involved 7619 participants, aged 11 to 90 years. There were 2978 participants in oral mucositis trials, 2031 participants in herpes labialis, 1052 participants in recurrent aphthous stomatitis (RAS), 76 participants in oral lichen planus (OLP), 210 participants in xerostomia, 131 participants in oral candidiasis, 126 participants in oral chronic graft-versus-host disease (cGVHD), 79 participants in leukoplakia, 24 participants in desquamative gingivitis, 4 participants in pemphigus and 8 participants in mucous membrane pemphigoid. The study's duration of the intervention varied in length, from two days to 6 months.

All RCTs or cross-over trials compared compounded topical drugs with or without cointerventions versus other active treatment or placebo (usually a preparation similar to the treatment, without the active ingredient). There was a variety of drug class that used as an active pharmaceutical ingredient (API) of compounded topical drugs on interventions. There were no included trials that compared the pharmacological approach with surgical treatments. Two trials on OLP case compared compounded topical medications with laser phototherapy ${ }^{[29,31]}$. One trial on oral mucositis compared compounded cryotherapy (ice balls) with placebo ${ }^{[83]}$. The characteristics of the included studies are presented in Supplementary Table 1.

\section{Effects of interventions}

The included trials were divided into ten subgroups according to the cases and two subgroups according to the dosage form category (liquid or semisolid). Of the 90 trials included, the forty-nine trials using a mouthwash as vehicle were as follows: thirty in oral mucositis ${ }^{[67-82,84-97]}$, six in $\operatorname{OLP}^{[21,24,28,32-34]}$, five in 
$\operatorname{RAS}^{[54,56,58,63,66]}$, three in xerostomia ${ }^{[38,42,43]}$, three in oral chronic GVHD ${ }^{[98-100]}$, one in leukoplakia ${ }^{[37]}$, and one in oral candidiasis ${ }^{[44]}$. The other forty-one trials used a semisolid preparation as a vehicle. The API was compounded with a mucoadhesive base, either in orabase or another excipient such as hydroxyethylcellulose gel. There were different interventions, comparisons, dosages, concentrations, vehicles, and time of application used in the included trials, along with a range of outcome measures and available data, making it difficult to meta-analyse the data. Of 90 studies, twenty-seven studies were included in the meta-analysis ${ }^{[14,16,22,23,29,39,40,48,49,55,59,61,64,67-69,76-79,80-82,84,87,88,96]}$.

\section{Clinical resolution of oral lesions}

Oral lichen planus. Seven trials compared the efficacy of clobetasol proprionate ointment $0.05 \%$ in mucoadhesive base versus different dose of other corticosteroids or other active treatment ${ }^{[13,14,16,17,22,23,29]}$, but only five trials provided data for meta-analysis ${ }^{[14,16,22,23,29]}$. Clobetasol increased clinical resolution of oral lesion in OLP by $16 \%$ compared to those without treatment $(\mathrm{RR}=1.16,95 \% \mathrm{CI}$ : 0.65-2.09, five studies with 181 participants). There was evidence of substantial or high heterogeneity in the included trials $\left(\mathrm{I}^{2}=81 \%, P\right.$ $=0.0004$ ) [Supplementary Figure 4A].

Xerostomia. A 46\% reduction of oral dryness severity was observed using pilocarpine $\mathrm{HCl} 5 \mathrm{mg}$ lozenge (RR $=1.54,95 \%$ CI: 1.03-2.28, two studies with 67 participants ${ }^{[39,40]}$. There was no evidence of heterogeneity in both trials $\left(\mathrm{I}^{2}=0 \%, P=0.55\right)$ [Supplementary Figure $4 \mathrm{~B}$ ].

Herpes labialis. It was $23 \%$ less likely to develop oral ulcer in herpes labialis in the treatment group compared to placebo $(\mathrm{RR}=0.77,95 \% \mathrm{CI} \text { : 0.69-0.85, } P<0.0001 \text {, two studies with } 1.187 \text { participants })^{[48,49]}$. There was no evidence of heterogeneity in both trials $\left(\mathrm{I}^{2}=0 \%, P=0.56\right)$ [Supplementary Figure $4 \mathrm{C}$ ].

Recurrent aphthous stomatitis. An increase of 33\% clinical resolution of oral lesions was observed using amlexanox $5 \%$ in mucoadhesive base $(\mathrm{RR}=1.33 \text {, 95\%CI: } 1.16-1.51 \text {, two studies with } 425 \text { participants })^{[55,59]}$. There was evidence of low heterogeneity in both trials $\left(\mathrm{I}^{2}=32 \%, P=0.23\right)$ [Supplementary Figure $4 \mathrm{D}$ ]. Participants who used doxycycline hyclate $100 \mathrm{mg}$ in denture adhesive base reported faster healing, 2 days sooner, than those with placebo $(\mathrm{MD}=-2.00,95 \% \mathrm{CI}:-2.63 \text { to }-1.36 \text {, two studies with } 80 \text { participants })^{[61,64]}$. There was evidence of substantial or medium heterogeneity in both trials $\left(\mathrm{I}^{2}=62 \%, P=0.10\right)$ [Supplementary Figure $4 \mathrm{E}]$.

Oral mucositis. Five trials compared the efficacy of allopurinol mouthwash with different dose $(1-6 \mathrm{mg} / \mathrm{mL})$ versus placebo or other active treatment ${ }^{[67,68,84,85,87]}$, but only four trials provided data for metaanalysis ${ }^{[67,68,84,87]}$. Participants who used allopurinol mouthwash were $26 \%$ less likely to experience greater oral mucositis severity (grade $0 v s$. other grades) than those with placebo or other active treatment (RR $=0.74,95 \%$ CI: 0.27-2.04, four studies with 213 participants). There was evidence of substantial or high heterogeneity in the included trials $\left(\mathrm{I}^{2}=86 \%, P<0.0001\right)$ [Supplementary Figure $4 \mathrm{~F}$ ]. Seven trials compared the efficacy of granulocyte-macrophage colony-stimulating factor (GM-CSF) mouthwash versus placebo or other active treatment ${ }^{[69,73-75,77-79]}$, but only four trials provided data for meta-analysis ${ }^{[69,77-79]}$. Participants who used GM-CSF mouthwash were 15\% less likely to experience severe oral mucositis (grade 0 vs. other grades) than those with placebo or other active treatment ( $R R=1.15,95 \% \mathrm{CI}$ : 0.50-2.65, four studies with 210 participants). There was evidence of substantial or medium heterogeneity in the included trials $\left(\mathrm{I}^{2}=\right.$ $55 \%, P=0.08$ ) [Supplementary Figure $4 \mathrm{G}$ ]. There was a $17 \%$ improvement in oral mucositis severity using iseganan $0.3 \%$ mouthwash $\left(\mathrm{RR}=1.18,95 \% \mathrm{CI}\right.$ : 0.99-1.93, three studies with 1.249 participants ${ }^{[80-82]}$. There was no evidence of heterogeneity in the included trials $\left(\mathrm{I}^{2}=0 \%, P=0.85\right)$ [Supplementary Figure $4 \mathrm{H}$ ].

\section{Pain resolution}

Herpes labialis. There was low-quality evidence that acyclovir 5\% compounded with hydrocortisone $1 \%$ cream (ME-609) was more effective than placebo in decreasing the pain or tenderness of ulcerative lesions 
of herpes labialis ( $\mathrm{RR}=0.98,95 \% \mathrm{CI}$ : 0.94-1.03, two studies with 639 participants $)^{[48,49]}$. There was substantial or medium heterogeneity in both trials $\left(\mathrm{I}^{2}=53 \%, P=0.15\right)$ [Supplementary Figure $4 \mathrm{I}$ ].

Oral mucositis. Participants treated with iseganan $0.3 \%$ mouthwash were more likely to experience pain relief $(0.62 x)$ sooner than those without treatment $(\mathrm{MD}=-0.62,95 \% \mathrm{CI}:-1.07$ to -0.17 ; $\mathrm{MD}=-0.28,95 \% \mathrm{CI}$ : -0.47 to -0.09 , two studies with 825 participants $)^{[80,81]}$. There was low heterogeneity in the included trials $\left(\mathrm{I}^{2}=0 \%, P=0.52 ; \mathrm{I}^{2}=16 \%, P=0.27\right)$ [Supplementary Figure $\left.4 \mathrm{~J}\right]$. Participants treated with morphine $0.2 \%$ mouthwash were more likely to experience pain relief $(1.99 \mathrm{x})$ sooner than those without treatment $(\mathrm{MD}=$ $-1.99,95 \% \mathrm{CI}-4.02$ to 0.03 , three studies with 63 participants $)^{[76,88,96]}$. There was substantial heterogeneity in the included trials $\left(\mathrm{I}^{2}=76 \%, P=0.02\right)$ [Supplementary Figure $4 \mathrm{~K}$ ].

\section{Adverse events}

Twenty-seven out of ninety studies clearly stated that there were no AEs of interventio $\mathrm{ns}^{[11,13,16,20,22,35,37,40,42,47,48,54-59,64,68,70,73,74,76,77,88,92,95]}$. Twenty-seven studies did not clearly state or report AEs of int erventions ${ }^{[10,12,21,24,26,33,45,46,50,52,53,63,65,67,71,75,78,79,83-87,89,90,94,97]}$. Oral candidiasis, burning sensation, taste alteration, and gastrointestinal (GI) symptoms (nausea, dyspepsia) were the most common AEs reported using compounded topical corticosteroids or immunosuppressants (tacrolimus) in OLP studies ${ }^{[14,15,17-19,23,25,27,29,34]}$, and in oral cGVHD studies ${ }^{[98-100]}$. Erythema was the AE of intervention (ketorolac) in the leukoplakia $\operatorname{study}^{[36]}$. Nausea, sweating, and urinary frequency were the most common AEs reported in xerostomia studies using a cholinergic agonist (pilocarpine, physostigmine) ${ }^{[38,39,41,43]}$. Transient mild GI discomfort using fluconazole mouthwash was observed in the oral candidiasis study ${ }^{[4]}$. Nasopharyngitis, headache, dry lips, burning sensation on the lips were the most commonly reported AEs using topical acyclovir compounded with corticosteroids ${ }^{[49]}$, or 2 -HP $3 \mathrm{CD}$ in herpes labialis studies ${ }^{[51]}$. Transient pain and bitter or uncomfortable sensation were the most common AEs reported in RAS studies using doxycycline or minocycline ${ }^{[00,61,66]}$, and corticosteroids (clobetasol) ${ }^{[62]}$. In oral mucositis studies, numbness was the most common AE reported using magic mouthwash ${ }^{[72]}$, nausea and vomiting using iseganan $0.3 \%$ mouthwash ${ }^{[80-82]}$, or phenylbutyrate mouthwash ${ }^{[91]}$, burning sensation and increased drowsiness using doxepin rinse ${ }^{[93]}$, and intolerable taste using morphine mouthwash ${ }^{[96]}$.

\section{DISCUSSION}

The results showed that clobetasol propionate ointment $0.05 \%$ in the mucoadhesive base was not superior to different doses of other corticosteroids or other active treatment but may be beneficial to improve the ulcerative lesion in symptomatic OLP. Although potent topical corticosteroids (TCs) are considered to be the first-line of treatment for symptomatic OLP at any site, it is assumed that the response varies from individual to individual ${ }^{[101,102]}$. Two earlier systematic reviews by Chamani et al. ${ }^{[102]}$ and Lodi et al ${ }^{[103]}$ concluded that there was insufficient evidence to support the superior effectiveness of any specific TC over another in the treatment of symptomatic $\mathrm{OLP}^{[101,103]}$. Nonetheless, a systematic review by GarcíaPola et al.$^{[101]}$ recommends the use of topical clobetasol propionate at 0.025\%-0.05\%, applied 2-3 times a day for 3 weeks, decreasing its frequency of application progressively according to the patients' response, and limiting its use to a maximum of 6 months, for the atrophic-erosive forms that do not respond to intralesional injection of betamethasone or triamcinolone $e^{[102]}$.

The use of pilocarpine $\mathrm{HCl} 5 \mathrm{mg}$ lozenge may be effective, where it reduced $46 \%$ xerostomia severity for radiation-induced xerostomia in patients with head and neck cancer. The result is in accordance with two previously systematic reviews by Cheng et al. ${ }^{[104]}$ and Yang et al. ${ }^{[105]}$, which found that pilocarpine may reduce radiation-induced xerostomia, particularly at a dose of $5 \mathrm{mg}, 3$ times daily ${ }^{[105]}$, but clinical trials may need to be performed to further validate that pilocarpine therapy is an effective and safe treatment for radiation-induced xerostomia ${ }^{[104]}$. 
In herpes labialis, the results suggest that acyclovir 5\% compounded with hydrocortisone $1 \%$ cream (ME-609) has a significant effect in reducing oral ulcer development and support earlier systematic review by Rosa et al. ${ }^{[106]}$ demonstrating a beneficial effect of early episodic treatment with the combination of an antiviral and corticosteroid. Combined antiviral and corticosteroid therapy may have additive effects. The vasoconstriction mediated by corticosteroid would increase the dermal concentration of the antiviral. The use of the compounded topical preparation of antiviral and corticosteroid (ME-609) may be effective to reduce the development of oral ulcers but not for pain resolution in herpes labialis.

The use of amlexanox 5\% in the mucoadhesive base for clinical resolution of RAS may be effective. A systematic review by Maheswari and Shanmugasundaram ${ }^{[107]}$ concluded that topical application of 5\% amlexanox, mainly when used from the prodromal stage until complete healing for four times a day, may increase healing time and reduce pain, but still need further study in terms of prevention of recurrence. In participants using doxycycline hyclate $100 \mathrm{mg}$ in denture adhesive base, there was faster healing time, 2 days sooner on the oral lesion of RAS. A previous systematic review evaluated the effects of tetracycline (doxycycline) in semisolid preparations for treating RAS $^{[108]}$, but a review by Staines and Greenwood ${ }^{[109]}$ reported that whether tetracycline mouthwash works is still in question, as the evidence was weak and limited to two small RCTs. Doxycycline hyclate $100 \mathrm{mg}$ in denture adhesive base may achieve faster healing on the oral lesion of RAS.

In oral mucositis, allopurinol, GM-CSF, or iseganan $0.3 \%$ mouthwash was not superior to placebo or other active treatment. A systematic review by Jensen et al. ${ }^{[110]}$ reported that no guidelines were possible due to insufficient or conflicting evidence in using allopurinol mouthwash for the management of oral mucositis. Clarkson et al. ${ }^{[111]}$, in their systematic review (2010), reported that the use of systemic or topical GM-CSF cannot currently be recommended for the prevention or treatment of oral mucositis. Saunders et al. ${ }^{[112]}$, in their systematic review, reported that iseganan mouthwash should not be used for the prevention of oral mucositis in hematopoietic stem cell transplant (HSCT) patients receiving high-dose chemotherapy with or without total body irradiation or in patients receiving head and neck radiation therapy or chemoradiotherapy. Due to the very low quality of evidence, using allopurinol, GM-CSF, or iseganan 0.3\% mouthwash to improve oral mucositis severity is not recommended. Participants who used morphine $0.2 \%$ mouthwash were less likely to experience oral pain than those without treatment, which was in accordance with two previous systematic reviews demonstrating that morphine can control of mucositis pain ${ }^{[111,12]}$. Morphine $0.2 \%$ mouthwash can be effective for the management of pain due to oral mucositis in patients receiving chemoradiation for head and neck cancer ${ }^{[112]}$. The effectiveness of pain relief may be achieved with 10-15 mL and can be used for 2-3 hours in patients with mucositis pain ${ }^{[113]}$.

To the best of our knowledge, this review was the first study to attempt to determine the efficacy and safety of topical compound medications in oral medicine cases. Mouthwash and semisolid preparations, either in gels, creams, or pastes (in mucoadhesive base) were the most used vehicles for local drug delivery, but with different API, dosages, concentrations, or duration of application. The challenges in topical drug delivery for oral mucosal diseases relate to overcoming the permeability of the oral mucosa, protecting drugs from enzymatic environments, and ensuring the drugs reach their target at therapeutic concentrations $^{[3]}$. Moreover, there are very few topical formulations, commercially available, that have been designed specifically for oral mucosal diseases. This review is limited due to the study question being very broad. Other limitations include substantial clinical and methodological heterogeneity such as a wide range of interventions being assessed and a lack of uniformity in the outcome measures employed to assess treatment efficacy, making it difficult to evaluate, compare, and pool the data for meta-analysis. Taylor et al. ${ }^{[14]}$ stated that to use EBP in oral medicine which is produced by high-quality systematic review and metaanalysis, there needs to be a future improvement of methodology of oral medicine intervention trials such as the use of PROMs and core outcome sets. There is a critical need to standardise the methodology 
of oral mucosal disease intervention trials mainly in terms of the assessment used (in each subgroup of diseases with similar characteristics). Further trials should measure the outcomes of symptoms and clinical assessment using standardised measures. Furthermore, future trials of topical drug delivery for oral mucosal diseases should develop and produce commercially available drugs that are clinically cost-effective, easy to use, or practicable across the globe.

In conclusion, Some compounded topical medications were recommended for the management of oral medicine cases, such as the compounded topical combination of antiviral with corticosteroids for herpes labialis, clobetasol propionate $0.05 \%$ in the mucoadhesive base for oral lichen planus, pilocarpine $\mathrm{HCl} 5 \mathrm{mg}$ lozenge for radiation-induced xerostomia in head and neck cancer patients, amlexanox 5\% in mucoadhesive base and doxycycline hyclate $100 \mathrm{mg}$ in denture adhesive base for recurrent aphthous stomatitis, and morphine $0.2 \%$ mouthwash in controlling oral mucositis pain. Future well-designed studies using standardised measures are needed to provide high-quality evidence in evaluating the efficacy and safety of compounded topical medications for the management of oral mucosal diseases.

\section{DECLARATIONS}

\section{Acknowledgments}

We would like to thank Evan Susandi (Biostatistician, Department of Internal Medicine, Faculty of Medicine, Padjadjaran University, Dr. Hasan Sadikin Hospital, Bandung, Indonesia) for participating in data analysis using Review Manager 5.3.

\section{Authors' contributions}

Made substantial contributions to conception and design of the study, prepared figures and/or tables, and performed data analysis and interpretation: Margono HB

Review and editing: Sufiawati I

\section{Availability of data and materials}

The data supporting their findings can be found as supplementary information in the journal.

\section{Financial support and sponsorship}

None.

\section{Conflicts of interest}

Both authors declared that there are no conflicts of interest.

\section{Ethical approval and consent to participate}

Not applicable.

\section{Consent for publication}

Not applicable.

\section{Copyright}

(c) The Author(s) 2020.

\section{REFERENCES}

1. Scully C, Miller CS, Aguirre Urizar JM, Alajbeg I, Almeida OP, et al. Oral medicine (stomatology) across the globe: birth, growth, and future. Oral Surg Oral Med Oral Pathol Oral Radiol 2016;121:149-57.e5.

2. Radulescu M. The pharmacologic management of common lesions of the oral cavity. Dent Clin North Am 2016;60:407-20.

3. Sankar V, Hearnden V, Hull K, Juras DV, Greenberg MS, et al. Local drug delivery for oral mucosal diseases: challenges and 
opportunities. Oral Dis 2011;17 Suppl 1:73-84.

4. Stock S, Rubino K, Woo SB, Margolis A, Thomas I, et al. Utilization of compounded medications in an oral medicine practice. Int J Pharm Compd 2016;20:155-8.

5. Liberati A, Altman DG, Tetzlaff J, Mulrow C, Gøtzsche PC, et al. The PRISMA statement for reporting systematic reviews and metaanalyses of studies that evaluate health care interventions: explanation and elaboration. PLoS Med 2009;6:e1000100.

6. WHO. WHO expert committee on specifications for pharmaceutical preparations: WHO technical report series (Report No. 50). Italy: WHO Press; 2016.

7. Higgins JPT, Sterne JAC, Savović J, Page MJ, Hróbjartsson A, et al. A revised tool for assessing risk of bias in randomized trials. In: Chandler J, McKenzie J, Boutron I, Welch V, editors. Cochrane Methods. Cochrane Database Syst Rev 2016;10:29-31.

8. Higgins JPT, Green S. Cochrane handbook for systematic review of interventions. 2011 March [Cited 2017 July 20]. Available from: http://handbook-5-1.cochrane.org. [Last accessed on 17 Aug 2020]

9. Schünemann H, Brożek J, Guyatt G, Oxman A, editors. GRADE handbook. 2013 Oct [Cited 2017 July 20]. Available from: http://gdt. guidelinedevelopment.org/app/handbook/handbook.html. [Last accessed on 17 Aug 2020]

10. Lozada-Nur FI, Silverman S. Topically applied fluocinonide in an adhesive base in the treatment of oral vesiculoerosive diseases. Arch Dermatol 1980;116:889-901.

11. Thongprasom K, Luangjarmekorn L, Sererat T, Taweesap W. Relative efficacy of fluocinolone acetonide compared with triamcinolone acetonide in treatment of oral lichen planus. Journal of Oral Pathol Med 1992;21:456-8.

12. Voute ABE, Schulten EAJM, Langendijk PNJ, Kostense PJ, van der waal I. Fluocinonide in an adhesive base for treatment of oral lichen planus: a double-blind, placebo-controlled clinical study. Oral Surg Oral Med Oral Pathol 1993;75: 181-5.

13. Lozada-Nur FI, Miranda C, Maliksi R. Double-blind clinical trial of $0.05 \%$ clobetasol propionate ointment in orabase and $0.05 \%$ fluocinonide ointment in orabase in the treatment of patients with oral vesiculoerosive diseases. Oral Surg Oral Med Oral Pathol 1994;77:598-604.

14. Rodstrom PO, Hakebergl M, Jontelll M, Nordin P. Erosive oral lichen planus treated with clobetasol propionate and triamcinolone acetonide in orabase: a double-blind clinical trial. J Dermatol Treat 1994;5:7-10.

15. Buajeeb W, Kraivaphan P, Pobrurksa C. Efficacy of topical retinoic acid compared with topical fluocinolone acetonide in the treatment of oral lichen planus. Oral Surg Oral Med Oral Pathol 1997;83:21-5.

16. Carbone M, Conrotto D, Carrozzo M, Broccoletti R, Gandolfo S, et al. Topical corticosteroids in association with miconazole and chlorhexidine in the long-term management of atrophic-erosive oral lichen planus: a placebo-controlled and comparative study between clobetasol and fluocinonide. Oral Dis 1999;5:44-9.

17. Lo Muzio L, Valle AD, Mignogna MD, Pannone G, Bucci P, et al. The treatment of oral aphthous ulceration or erosive lichen planus with topical clobetasol propionate in three preparations: a clinical and pilot study on 54 patients. J Oral Pathol Med 2001;30:611-7.

18. Campisi G, Giandalia G, De Caro V, Di Liberto C, Arico P, et al. A new delivery system of clobetasol-17-propionate (lipid-loaded microspheres $0.025 \%$ ) compared with a conventional formulation (lipophilic ointment in a hydrophilic phase $0.025 \%$ ) in topical treatment of atrophic /erosive oral lichen planus. A phase IV, randomized, observer-blinded, parallel group clinical trial. Br J Dermatol 2004;150:984-90.

19. Conrotto D, Carbone M, Carrozzo M, Arduino P, Broccoletti R, et al. Cyclosporine vs. clobetasol in the topical management of atrophic and erosive oral lichen planus: a double-blind, randomized controlled trial. Br J Dermatol 2006;154:139-45.

20. Scardina GA, Messina P, Carini F, Maresi E. A randomized trial assessing the effectiveness of different concentrations of isotretinoin in the management of lichen planus. Int J Oral Maxillofac 2006;35:67-71.

21. Javadzadeh A, Vatanpour H, Delavarian Z, Momajed A, Esmaeily H, et al. Efficacy of clobetasol, ketoconazole and amitriptyline mouthwash on oral lichen planus. IJPR 2008;7:171-8.

22. Carbone M, Arduino PG, Carrozzo M, Caiazzo G, Broccoletti R, et al. Topical clobetasol in the treatment of atrophic-erosive oral lichen planus: a randomized controlled trial to compare two preparations with different concentrations. J Oral Pathol Med 2009;38:227-33.

23. Cilurzo F, Gennari CGM, Selmin F, Epstein JB, Gaeta GM, et al. A new mucoadhesive dosage form for the management of oral lichen planus: Formulation study and clinical study. Eur J Pharm and Biopharm 2010;76:437-42.

24. Dalirsani Z, Zenouz AT, Mehdipour M, Alavi F, Javadzadeh Y. Comparison of the effect of combination of triamcinolone acetonide and vitamin a mouthwash with triamcinolone mouthwash alone on oral lichen planus. JODDD 2010;4:21-4.

25. Wu Y, Zhou G, Zeng H, Xiong CR, Lin M, et al. A randomized double-blind, positive-control trial of topical thalidomide in erosive oral lichen planus. Oral Surg Oral Med Oral Pathol Oral Radiol Endod 2010;110:188-95.

26. Ahadian H, Akhavan Karbassi MH, Vahidi AR, Owlia F. Comparison of two corticosteroids mouthwashes in treatment of symptomatic oral lichen planus. J Dent Shiraz Univ Med Scien 2012;13:49-53.

27. Arduino PG1, Carbone M, Della Ferrera F, Elia A, Conrotto D, et al. Pimecrolimus vs. tacrolimus for the topical treatment of unresponsive oral erosive lichen planus: a 8 week randomized double-blind controlled study. J Eur Acad Dermatol Venereol 2013;28:475-82.

28. Lee YC, Shin SY, Kim SW, Eun YG. Intralesional injection versus mouth rinse of triamcinolone acetonide in oral lichen planus: a randomized controlled study. Otolaryngol Head Neck Surg 2013;148:443-9.

29. Dillenburg CS, Martins MAT, Munerato MC, Marques MM, Carrard VC, et al. Efficacy of laser phototherapy in comparison to clobetasol for the treatment of oral lichen planus: a randomized controlled trial. Journal of Biomed Optics 2014;19:1-9.

30. Azizi A, Dadrasb OG, Jafaric M, Ghadimd NM, Lawafe S, et al. Efficacy of $0.1 \%$ triamcinolone with nanoliposomal carrier formulation in orabase for oral lichen planus patients: A clinical trial. Eur J Integr Med 2015;460:1-6.

31. Jajarm HH, Falaki F, Sanatkhani M, Ahmadzadeh M, Ahrari F, et al. A comparative study of toluidine blue-mediated photodynamic 
therapy versus topical corticosteroids in the treatment of erosive-atrophic oral lichen planus: a randomized clinical controlled trial. Lasers Med Sci 2015;30:1475-80.

32. Hambly JL, Haywood A, Hattingh L, Nair RG. Comparison between self-formulation and compound-formulation dexamethasone mouth rinse for oral lichen planus: a pilot, randomized, cross-over trial. J Investig Clin Dent 2017;8:1-7.

33. Vaseemuddin S. Comparison of $0.1 \%$ dexamethasone and $0.2 \%$ triamcinolone acetonide mouthwashes for treatment of oral lichen planusA clinical study. Int J Com Health Med Res 2017;3:11-4.

34. Vathanasanti A, Kanjanabuch P. Fluocinolone acetonide $0.01 \%$ and dexamethasone $0.1 \%$ mouthwash in the treatment of symptomatic oral lichen planus. Adv Dent Oral Health 2017;3:555611.

35. Corrocher G, Di Lorenzo G, Mansueto P, Martinelli N, Esposito-Pelitteri M, et al. Comparison of topical tacrolimus $0.1 \%$ in pectin ointment with clobetasol $0.5 \%$ ointment in adults with moderate to severe desquamative gingivitis: a 4-week, randomized, double-blind clinical trial. Clin Ther 2006;28:1296-302.

36. Epstein JB, Wong FLW, Millner A, Le ND. Topical bleomycin treatment of oral leukoplakia: a randomized double-blind clinical trial. Head Neck 1994;16:539-44.

37. Mulshine JL, Atkinson JC, Greer RO, Papadimitrakopoulou VA, Van Waes C, et al. Randomized, double blind, placebo-controlled phase IIB trial of the cyclooxygenase inhibitor ketorolac as an oral rinse in oropharyngeal leukoplakia. Clin Cancer Res 2004;10:1565-73.

38. Davies AN, Singer J. A comparison of artificial saliva and pilocarpine in radiation-induced xerostomia. J Laryngol Otol 1994;108:663-5.

39. Hamlar DD, Schuller DE, Gahbauer RA, Buerki RA, Staubus AE, et al. Determination of the efficacy of topical oral pilocarpine for postirradiation xerostomia in patients with head and neck carcinoma. Laryngoscope 1996;106:972-6.

40. Taweechaisupapong S, Pesee M, Aromdee C, Laopaiboon M, Khunkitti W. Efficacy of pilocarpine lozenge for post-radiation xerostomia in patients with head and neck cancer. Aust Dent J 2006;51:333-7.

41. Khosravani N, Birkhed D, Ekström J. The cholinesterase inhibitor physostigmine for the local treatment of dry mouth: a randomized study. Eur J Oral Sci 2009;117:209-17.

42. Kim JH, Ahn HJ, Choi JH, Jung DW, Kwon JS. Effect of $0.1 \%$ pilocarpine mouthwash on xerostomia: double-blind, randomised controlled trial. J Oral Rehabil 2014;41:226-35.

43. Tanigawa T, Yamashita J, Sato T, Shinohara A, Shibata R, et al. Efficacy and safety of pilocarpine mouthwash in elderly patients with xerostomia. Spec Care Dentist 2015;35:164-9.

44. Sholapurkar AA, Pai KM, Rao S. Comparison of efficacy of fluconazole mouthrinse and clotrimazole mouthpaint in the treatment of oral candidiasis. Australian Dental Journal 2009;54:341-6.

45. Khozeimeh F, Shahtalebi MA, Noori M, Savabi O. Comparative evaluation of ketoconazole tablet and topical ketoconazole $2 \%$ in orabase in treatment of candida-infected denture stomatitis. J Contemp Dent Pract 2010;11:17-24.

46. Czerninski R, Pikovsky A, Gati I, Friedman M, Steinberg D. Comparison of the efficacy of a novel sustained release clotrimazole varnish and clotrimazole troches for the treatment of oral candidiasis. Clin Oral Investig 2015;19:467-73.

47. Kaminester LH, Pariser RJ, Pariser DM, Weiss JS, Shavin JS, et al. A double-blind, placebo controlled study of topical tetracaine in the treatment of herpes labialis. J Am Acad Dermatol 1999;41:996-1001.

48. Evans TG, Bernstein DI, Raborn GW, Harmenberg J, Kowalski J, et al. Double-blind, randomized, placebo-controlled study of topical 5\% acyclovir-1\% hydrocorticone cream (ME-609) for the treatment of UV radiation-induced herpes labialis. Antimicrob Agents Chemother 2002;46:1870-4.

49. Hull CM, Harmenberg J, Arlander E, Aoki F, Bring J, et al. Early treatment of cold sores with topical ME-609 decreases the frequency of ulcerative lesions: a randomized, double-bind, placebo-controlled, patient-initiated cinica trial. J Am Acad Dermatol 2011;64:696.e1-11.

50. Skulason S, Holbrook WP, Thormar H, Gunnarsson GB, Krsitmundsdottir T. A study of the clinical activity of a gel combining monocaprin and doxycycline: a novel treatment for herpes labialis. J Oral Pathol Med 2012;41:61-7.

51. Senti G, Iannaccone R, Graf N, Felder M, Tay F, et al. A randomized, double-blind, placebo-controlled study to test the efficacy of topical 2-hydroxypropyl-Beta-cyclodextrin in the prophylaxis of recurrent herpes labialis. Dermatology 2013;226:247-52.

52. Merchant HW, Gangarosa LP, Glassman AB, Sobel RE. Betamethasone-17-benzoate in the treatment of recurrent aphthous ulcers. Oral Surg Oral Med Oral Pathol 1978;45:870-5.

53. Ylikontiola L, Sorsa T, Häyrinen-Immonen R, Salo T. Doxymycine-cyanoacrylate treatment of recurrent aphthous ulcers. Oral Surg Oral Med Oral Pathol Oral Radiol Endod 1997;83:329-33.

54. Darbandi A, Ganbari A. Evaluation of the effect of a clobetasol propionate and nystatin mouthwash on recurrent aphthous stomatitis. Front Dent 2006;3:117-21.

55. Liu J, Zeng X, Chen Q, Cai Y, Chen F, et al. An evaluation on the efficacy and safety of amlexanox oral adhesive tablets in the treatment of recurrent minor aphthous ulceration in a Chinese cohort: a randomized, double-blind, vehicle-controlled, unparallel multicenter clinical trial. Oral Surg Oral Med Oral Pathol Oral Radiol Endod 2006;102:475-81.

56. Gorsky M, Epstein J, Rabenstein S, Elishoov H, Yarom N. Topical minocycline and tetracycline rinses in treatment of recurrent aphthous stomatitis: a randomized cross-over study. Dermatol Online J 2007;13:1.

57. Rodriguez M, Rubio JA, Sanchez R. Effectiveness of two oral pastes for the treatment of recurrent aphthous stomatitis. Oral Dis 2007;13:490-4.

58. Gorsky M, Epstein J, Raviv A, Yaniv R, Truelove E. Topical minocycline for managing symptoms of recurrent aphthous stomatitis. Spec Care Dentist 2008;28:27-31.

59. Meng W, Dong Y, Liu J, Wang Z, Zhong X, et al. A clinical of amlexanox oral adhesive pellicles in the treatment of recurrent aphthous stomatitis and comparison with amlexanox oral tablets: a randomized, placebo controlled, blinded, multicenter clinical trial. Trials 
2009;10:30,

60. Skulason S, Holbrook WP, Kristmundsdottir T. Clinical assessment of the effect of a matrix metalloproteinase inhibitor on aphthous ulcers. Acta Odontol Scand 2009;67:25-9.

61. Vijayabala GS, Kalappanavar AN, Annigeri RG, Sudarshan R, Shettar SS. Single application of topical doxycycline hyclate in the management of recurrent aphthous stomatitis. Oral Surg Oral Med Oral Pathol Oral Radiol 2013;116:440-6.

62. Ronal A, Permana G, Rahmayanti F. Effectiveness of clobetasol propionate $0.05 \%$ bioadhesive gel in minor recurrent aphthous stomatitis. Oral medicine [thesis]. Jakarta: Universitas Indonesia; 2014.

63. Mehdipour M, Zenooz AT, Sohrabi A, Gholizadeh N, Bahramian A, et al. A comparison of the effect of triamcinolone ointment and mouthwash with or without zinc on the healing process of aphthous stomatitis lesions. JODDD 2016;10:87-91.

64. Chandak R, Sonule S, Chandak M, Rawlani S, Gaikwad R. Efficacy of single application of topical doxycycline hyclate and triamcinolone acetonide in denture adhesive in the management of recurrent aphthous stomatitis: a comparative study. J Oral Res Rev 2017;9:72-6.

65. Mojtahedi N, Ghalayani P, Golestannejad Z, Davari A, Shahi H. Comparative evaluation of two forms of drugs: patch \& lotion of clobetasol, on recovery indicators of aphthous stomatitis. Ann Dent Spec 2017;5:27-32.

66. Yarom N, Zelig K, Epstein JB, Gorsky M. The efficacy of minocycline mouth rinses on the symptoms associated with recurrent aphthous stomatitis: a randomized, double-blind, crossover study assessing different doses of oral rinses. Oral Surg Oral Med Oral Pathol Oral Radiol 2017;123:675-9.

67. Loprinzi CL, Cianflone SG, Dose AM, Etzell PS, Burnham NL, et al. A controlled evaluation of an allopurinol mouthwash as prophylaxis against 5-fluorouracil-induced stomatitis. Cancer 1990;65:1879-82.

68. Tsavaris NB, Komitsopoulou P, Tzannou I, Loucatou P, Tsaroucha-Noutsou A, et al. Decreased oral toxicity with the local use of allopurinol in patients who received high dose 5-fluorouracil. Sel Cancer Ther 1991;7:113-7.

69. Cartee L, Petros WP, Rosner GL, Gilbert C, Moore S, et al. Evaluation of GM-CSF mouthwash for prevention of chemotherapy-induced mucositis: a randomized, double-blind, dose-ranging study. Cytokine 1995;7:471-7.

70. Malik IA, Moid I, Haq S, Sabih M. A double-blind, placebo-controlled, randomized trial to evaluate the role of tetrachlorodecaoxide in the management of chemotherapy-induced oral mucositis. J Pain Symptom Manage 1997;14:82-7.

71. Karthaus M, Rosenthal C, Huebner G, Paul H, Elser C, et al. Effect of topical oral G-CSF on oral mucositis: a randomised placebocontrolled trial. Bone Marrow Transplant 1998;22:781-5.

72. Dodd MJ, Dibble SL, Miaskowski C, MacPhil L, Greenspan D, et al. Randomized clinical trial of the effectiveness of 3 commonly used mouthwashes to treat chemotherapy-induced mucositis. Oral Surg Oral Med Oral Pathol Oral Radiol Endod 2000;90:39-47.

73. Hejna M, Kostler WJ, Raderer M, Steger GG, Brodowicz T, et al. Decrease of duration and symptoms in chemotherapy-induced oral mucositis by topical GM-CSF: results of a prospective randomised trial. Euro J Cancer 2001;37:1994-2002.

74. Sprinzl GM, Galvan O, de Vries A, Ulmer H, Gunkel AR, et al. Local application of granulocyte-macrophage colony stimulating factor (GM-CSF) for the treatment of oral mucositis. Eur J Cancer 2001;37:2003-9.

75. van der Lelie H, Thomas BL, van Oers RH, Ek-Post M, Sjamsoedin SA, et al. Effect of locally applied GM-CSF on oral mucositis after stem cell transplantation: a prospective placebo-controlled double-blind study. Ann Hematol 2001;80:150-4.

76. Cerchietti LCA, Navigante AH, Bonomi MR, Zaderadjko MA, Menendez PR, et al. Effect of topical morphine for mucositis-associated pain following concomitant chemoradiotherapy for head and neck carcinoma. Cancer 2002;95: 2230-6.

77. Saarilahti K, Kajanti M, Joensuu T, Kouri M, Joensuu H. Comparison of granulocyte-macrophage colony-stimulating factor and sucralfate mouthwashes in the prevention of radiation-induced mucositis: a double-blind prospective randomized phase III study. Int J Radiat Oncol Biol Phys 2002;54:479-85.

78. Valcárcel D, Sanz MA Jr, Sureda A, Sala M, Muñoz L, et al. Mouth-washings with recombinant human granulocyte-macrophage colony stimulating factor (rhGM-CSF) do not improve grade III-IV oropharyngeal mucositis (OM) in patients with hematological malignancies undergoing stem cell transplantation. Results of a randomized double-blind placebo-controlled study. Bone Marrow Transplant 2002;29:783-7.

79. Dazzi C, Cariello A, Giovanis P, Monti M, Vertogen B, et al. Prophylaxis with GM-CSF mouthwashes does not reduce frequency and duration of severe oral mucositis in patients with solid tumors undergoing high-dose chemotherapy with autologous peripheral blood stem cell transplantation rescue: a double blind, randomized, placebo-controlled study. Ann Oncol 2003;14:559-63.

80. Giles FJ, Miller CB, Hurd DD, Wingard JR, Fleming TR, et al. A phase III, randomized, double-blind, placebo-controlled, multinational trial of iseganan for the prevention of oral mucositis in patients receiving stomatotoxic chemotherapy (PROMPT-CT trial). Leuk Lymphoma 2003;44:1165-72.

81. Giles FJ, Rodriguez R, Weisdorf D, Wingard JR, Martin PJ, et al. A phase III, randomized, double-blind, placebo-controlled, study of iseganan for the reduction of stomatitis in patients receiving stomatotoxic chemotherapy. Leuk Res 2004;28:559-65.

82. Trotti A, Garden A, Warde P, Symonds P, Langer C, et al. A multinational, randomized phase III trial of iseganan $\mathrm{HCl}$ oral solution for reducing the severity of oral mucositis in patients receiving radiotherapy for head-and-neck malignancy. Int J Radiat Oncol Biol Phys 2004;58:674-81.

83. Yokomizo H, Yoshimatsu K, Hashimoto M, Ishibashi K, Umehara A, et al. Prophylactic efficacy of allopurinol ice ball for leucovorin/5fluorouracil therapy-induced stomatitis. Anticancer Res 2004;24:1131-4.

84. Nazari M, Sadrolhefazi B, Nikoofar A, Erfan M, Azizian H, et al. Allopurinol mouthwash for prevention or alleviation radiotherapy induced oral mucositis: a randomized, placebo-controlled trial. Daru 2007;15:227-30.

85. Shabanloei R, Ahamdi F, Vaez J, Ansarin K, Hajizadeh E, et al. Allopurinol, Chamomile and normal saline mouthwashes for the prevention of chemotherapy-induced stomatitis. J Clin Diagn Res 2009;3:1537-42. 
86. Baharvand M, Sarrafi M, Alavi K, Moghaddam EJ. Efficacy of topical phenytoin on chemotherapy-induced oral mucositis; a pilot study. Daru 2010;18:46-50.

87. Panahi Y, Ala S, Saeedi M, Okhovatian A, Bazzaz N, et al. Allopurinol mouth rinse for prophylaxis of fluorouracil-induced mucositis. European Journal of Cancer Care 2010;19:308-12.

88. Vayne-Bossert P, Escher M, Gilbert de Vautibault C, Dulguerov P, Allal A, et al. Effect of topical morphine (mouthwash) on oral pain due to chemotherapy- and/or radiotherapy-induced mucositis: a randomized double-blinded study. J Palliat Med 2010;13:125-8.

89. Watanabe T, Ishihara M, Matsuura K, Mizuta K, Itoh Y. Polaprezinc prevents oral mucositis associated with radiochemotherapy in patients with head and neck cancer. Int J Cancer 2010;127:1984-90.

90. Mehdipour M, Zenooz AT, Kermani IA, Hosseinpour A. A comparison between zinc sulfate and chlorhexidine gluconate mouthwashes in the prevention of chemotherapy-induced oral mucositis. Daru 2011;19:71-3.

91. Yen SH, Wang LW, Lin YH, Jen YM, Chung YL. Phenylbutyrate mouthwash mitigates oral mucositis during radiotherapy or chemoradiotherapy in patients with head-and-neck cancer. Int J Radiation oncology Biol Phys 2012; 82:1463-70.

92. Lambrecht M, Mercier C, Geussens Y, Nuyts S. The effect of a supersaturated calcium phosphate mouth rinse on the development of oral mucositis in head and neck cancer patients treated with (chemo)radiation. Support Care Cancer 2013;21:2663-70.

93. Leenstra JL, Miller RC, Qin R, Martenson JA, Dornfeld KJ, et al. Doxepin rinse versus placebo in the treatment of acute oral mucositis pain in patients receiving head and neck radiotherapy with or without chemotherapy: a phase III, randomized, double-blind trial. J Clin Oncol 2014;32:1571-7.

94. Hosseinjani H, Hadjibabaie M, Gholami K, Javadi M, Radfar M, et al. The efficacy of erythropoietin mouthwash in prevention of oral mucositis in patients undergoing autologous hematopoietic SCT: a double-blind, randomized, placebo-controlled trial. Hematol Oncol 2017;35:106-12.

95. Lin JX, Fan ZY, Lin Q, Wu Q, Wu DH, et al. A comparison of dioctahedral smectite and iodine glycerine cream with topical mouth rinse in treatment of chemotherapy induced oral mucositis: a pilot study. Eur J Oncol Nurs 2015;19:136-41.

96. Sarvizadeh M, Hemati S, Meidani M, Ashouri M, Roayaei M, et al. Morphine mouthwash for the management of oral mucositis in patients with head and neck cancer. Adv Biomed Res 2015;4:44.

97. Ala S, Saeedi M, Janbabai G, Ganji R, Azhdari E, et al. Efficacy of sucralfate mouth wash in prevention of 5-fluorouacil induced oral mucositis: a prospective, randomized, double-blind, controlled trial. Nutr and Cancer 2016;68:456-63.

98. Park AR, La HO, Cho BS, Kim SJ, Lee BK, et al. Comparison of budesonide and dexamethasone for local treatment of oral chronic graftversus-host disease. Am J Health Syst Pharm 2013;70:1383-91.

99. Noce CW, Gomes A, Shcaira V, Corrêa ME, Moreira MC, et al. Randomized double-blind clinical trial comparing clobetasol and dexamethasone for the topical treatment of symptomatic oral chronic graft-versus-host disease. Biol Blood Marrow Transplant 2014;20:1163-8.

100. Treister N, Li S, Kim H, Lerman M, Sultan A, et al. An open-label phase II randomized trial of topical dexamethasone and tacrolimus solutions for the treatment of oral chronic graft-versus-host disease. Biol Blood Marrow Transplant 2016;22:2084-91.

101. García-Pola MJ, González-Álvarez L, Garcia-Martin JM. Treatment of oral lichen planus. Systematic review and therapeutic guide. Med Clin (Barc) 2017;149:351-62.

102. Chamani G, Rad M, Zarei MR, Lotfi S, Sadeghi M, et al. Efficacy of tacrolimus and clobetasol in the treatment of oral lichen planus: a systematic review and meta-analysis. Int J Dermatol 2015;54:996-1004.

103. Lodi G, Carrozzo M, Furness S, Thongprasom K. Interventions for treating oral lichen planus: a systematic review. Br J Dermatol 2012;166:938-47.

104. Cheng CQ, Xu H, Liu L, Wang RN, Liu YT, et al. Efficacy and safety of pilocarpine for radiation-induced xerostomia in patients with head and neck cancer: a systematic review and meta-analysis. J Am Dent Assoc 2016;147:236-43.

105. Yang WF, Liao GQ, Hakim SG, Ouyang DQ, Ringash J, et al. Is pilocarpine effective in preventing radiation-induced xerostomia? a systematic review and meta-analysis. Int J Radiat Oncol Biol Phys 2016;94:503-11.

106. Rosa MI, Souza SL, Farias BF, Pires PD, Dondossola ER, et al. Efficacy of Topical 5\% Acyclovir-1\% Hydrocortisone Cream (ME-609) for Treatment of Herpes Labialis: a systematic review. An Acad Bras Cienc 2015;87:1415-20.

107. Maheswari TNU, Shanmugasundaram P. Amlexanox in treatment of aphthous ulcers: A systematic review. Journal of Pharmacy Research 2013;6:214-7.

108. Piacentini M, Borghetti RL, Zancanaro de Figueiredo MA, Cherubini K, Goncalves Salum F. Doxycycline: an option in the treatment of ulcerated oral lesions? J Clin Pharm Ther 2019;44: 838-43.

109. Staines K, Greenwood M. Aphthous ulcers (recurrent). Systematic review 1303. BMJ Clinical Evidence. http://clinicalevidence.bmj.com/ x/systematic-review/1303/overview.html. [Last accessed on 17 Aug 2020].

110. Jensen SB, Jarvis V, Zadik Y, Barasch A, Ariyawardana A, et al. Systematic review of miscellaneous agents for the management of oral mucositis in cancer patients. Support Care Cancer 2013;21:3223-32.

111. Clarkson JE, Worthington HV, Furness S, McCabe M, Khalid T, et al. Interventions for treating oral mucositis for patients with cancer receiving treatment. Cochrane Database Syst Rev 2010;(8):CD001973.

112. Saunders DP, Epstein JB, Elad S, Allemano J, Bossi P, et al. Systematic review of antimicrobials, mucosal coating agents, anesthetics, and analgesics for the management of oral mucositis in cancer patients. Support Care Cancer 2013;21:3191-207.

113. Dutta K, Garg R. Morphine mouthwash in oral mucositis: a mini review. Palliat Med Hosp Care Open J 2016;2:26-9.

114. Taylor J, Walsh T, Worthington H, Brocklehust P, Pemberton MN, et al. Cochrane and the COMET initiative: developing the evidence base in oral medicine. BDJ 2017;223:729-32. 